\title{
Resilience phenomenon reflection
}

\author{
Elena Bayer $^{11}$, Stepan Avakov ${ }^{2}$, Nariné Grigoryan ${ }^{3}$, and Rouzanna Aroutyunyan ${ }^{4}$ \\ ${ }^{1}$ Chair of Social Pedagogy, Don State Technical University, 344000 Rostov-on-Don, \\ Russia \\ ${ }^{2}$ Don State Technical University, 344000 Rostov-on-Don, Russia \\ ${ }^{3}$ Chair of Medical Biology and Genetics, Rostov State Medical University, 344022 Rostov- \\ on-Don, Russia \\ ${ }^{4}$ Don State Technical University, 344000 Rostov-on-Don, Russia
}

\begin{abstract}
This theoretical research specifically emphasizes personal resilience phenomenon. Children's social activity is something that draws its significance from themselves; they must have a well-developed sense of personality and a clear understanding of their own role (their personal responsibility) in their closest social environment.

A mentee (a child from an orphanage) needs to shape his/her own personal identification; as a person, he/she should be able to count on his/her own developed resources such as resilience, and internal personal position towards the choice of lifetime values.

The article is a reflection on an approach to understanding the meaning of the personal growth conditions including the ways of structuring the teaching process that provides for the personal growth; a detailed model of interactions between eight structural components of an educational system as a social demand (state component), a targeted resilience buildup (projection component), a mentee (a child) (organization component), an educator preparedness (knowledge component), scientific and teaching information (constructive component), educational means of communication (communicative component), a tool of assessment (assessment and reflective component), and a follow-up educational system (prognostic component).
\end{abstract}

The concept of resilience is still absent from a New Philosophic Encyclopedia [1]. However, there are works of philosophers that deal with the ideas of "living" and thus suggest the ideas of resilience of that which is alive, or "living" [2].

In the meantime, Soviet-era and Russian published psychology vocabularies $[3,4,5]$ have no resilience as a concept.

Any educational practice is inimitable and always focuses on a specific individual of a specific age group. A community of educators have always been challenged by an intrinsic question, What makes a difference between a resilient child's operations in urgent, or critical, situations and operations of all other children?

Let us show you a number of situations from the lives of well-known people whose start of life was not very fortunate. A story of a professor of linguistics. He was born into a very unhappy family with no father and an alcoholic mother. The mother of this professor-to-be

\footnotetext{
${ }^{1}$ Corresponding author: zaluzhnaya.mari@mail.ru
} 
had eight children from different men. She almost never took care of her children. Except for him, only two more kids lived to become 40-year-olds.

So, why was this man with such an unfortunate start of life able to achieve a status of a much-respected person?

Another story. In a far-away West-Siberian town at Lake Baikal a family with two children tried hard to make their living. A father of the family was shell-shocked during the World War 2; his young wife could not stand the trial and they both fell deep into drinking alcohol. For days, their children stayed hungry locked at home and scared to death by constant fights between their ever-drunk parents and their pals. Their mother finally could not stand it, and left the family, only to be followed soon by the children who ended up living in the municipal sewage, as it was warm there. A brother died, but the girl survived, having eventually become a practicing scientist, and committed her life to studying children resilience. Moreover, there are so many examples like this...

In the history of humanity, there are many examples of lives of those who had to go through hardships and difficulties in their lives, the ones that testify of trials that they were able to overcome and ended up almost untouched by them. These are the people who were called "resilient" - those able to overcome hardships, to plan their life trajectories, and to take on a responsibility over every stage of their lives [6].

Sure enough, there are categories of victimized people, who think they are victims and reject any lesson from their trials and hardships. Unlike them, there are those having a high level of resilience who can find a positive element in their sufferings and thus they build up their lives as well as the lives of those around them filling it with positive content. [7].

We suppose it will be correct to note that resilience is a setting that an individual has to manage lifetime hardships with an assurance in his future success and no failures can bring him down.

How can we make the 'finish' a primary landmark of people's lives, not just the start?

According to a majority of scholars (B. G. Ananyev, V. S. Mukhina, et al.), creating a raison d'etre may happen in two ways.

According to V. S. Mukhina's vision, it happens by means of a person's claim to acknowledgement, which "affects the character of choosing the life trajectory and of identifying yourself with the traditional expectations when the social expectations motivate a person to command himself, "it is time to make a choice", "it is time to assure yourself in life (profession, family, personal internal accomplishments)" [8, p. 584]. Furthermore, as V. S. Mukhina suggests, if a person lacks "a critique over his own self, or shrewdness to foreknow the consequences of his inadequate claims, then it is highly probable that he may harm himself as a personality and/or start harming other people" [8, p. 584].

We can affirm that the self-making example supports a sense of personality and ensures a person's unique identification.

Austrian philosopher Franz K. H. H. Brentano (1830 - 1917), besides philosophy itself, studied psychology. He suggested, “... Psychic phenomena are truly available for research and must be researched as an own (individually gained) experience that is fully perceived by the individual". The scholar made psychological problems a subject of his research and was able to distinguish between the physical and psychological phenomena. He always underlined that the genitive (common) sign of the psychic phenomena (unlike the physical ones) was their intentionality since the conscience is always an attitude towards something" [9]. Intentionality, according to F. Brentano, is a "capacity to classify psychological phenomena into: a) imagination (representation as a pure presence of an object); b) judgments (affirmation or negation of the object); and c) sensations (love or hatred towards the object)" [9, p. 16].

A key definition of the essence of resilience by F. Brentano is, "A personal life experience of an individual that is fully perceived by the individual" [9, p. 17]. 
As we reflect on the phenomenon of resilience, we arrived to an opinion that resilience is a personal characteristic that is not passed genetically, but rather formed and developed throughout the lifetime of an individual.

Why is it important to research the phenomenon of resilience within the framework of an educational system of children preparation to independent living?

The resilience ensures a physical, emotional, and social wellbeing. It is an attitude that perpetuates value and meaning to life in all their senses. By including the internal personal resources, control, and challenges (meeting life challenges) a person can simultaneously grow, enrich its potential and overcome the stresses it faces along the way.

From the same starting point, when all the children are placed in the same type of circumstances since their birth, and can see the destructive life events (filth and impurity, betrayal, indignity, despise, etc.), some put all efforts to start living better while others can't even imagine there's an alternative to their living. Some reconcile to their living and become a copy of their parents while others - as we know it - overcome the negative influence by making their best to become a different person - a brave, strong, reliable, successful person, and a loving parent.

A success attitude through getting an education in demand, a profession (a trade), building a family, raising children, and enjoying healthy lifestyles is a key idea of this article.

It is obvious nowadays that restoration and development of basic principles of the traditional Russian upbringing are important. A mentee must perceive the risks he is running when making decisions. It will become possible if a mentee clearly understands his expectations and the type of risks (end result) he may have when diverse decisions are made. An educator's key position is to provide a mentee with a correct attitude to enable him to make a decision hic et hoc accompanied with a detailed analysis of each stage of the trajectory built.

The author's educational system puts a key task to develop children's perception of their role in the community, ability to assign a task and to solve it, the latter being the tool of building resilience. Such an approach teaches a mentee to analyze his life events, to understand much depends on how he plans his way of living, and that he is responsible for each stage of his way of life.

Since 2010, we have been implementing an educational system of building children resilience that proved itself a successful practice of a mentee preparation to an independent life in community and is based on a principle of adaptivity. The education based on this principle allows solving a problem that is typical for some Russian families and the children being raised at orphanages. Often children possess a bunch of theoretical knowledge, but they still have serious troubles in real live situations, which demand the resolution of specific problems in life.

So based on the above-mentioned approaches we have developed and tested a principle of the resilient person build-up.

At the first stage, it is suggested to include a mentee in the specific conditions of activity. The inclusion of the mentee in the circle of activities provides for him as a personality an opportunity to find something worth doing and interesting. A high level of inclusion brings him satisfaction of his position and activity. The absence of such inclusion generates a sense of alienation and rejection. A teenager feels "off life". Here is how S. R. Muddy's judgment supports the said, "If you feel confidence in you and in the benevolence of the world around you, you are contained in inclusion (marked by the author) [10, p. 265].

At the second stage, it is important to prolong effective methods of building up the personal characteristics that ensure further development of a mentee's resilience. The authors' approach presupposes that this stage will be implemented through a system of educational control, or education support of the mentee. A person with a sufficiently 
developed ability for self-control is able to choose his own life trajectory and ensure his personal growth with the means of self-control.

As the practice shows, an image of the future and the lifetime landmarks allow the mentee to live better in the present. Their readiness to independent resolutions of psychological and social problems is formed on the basis of internal and external resources.

A child ought to have a need of forming his own personal identity for a consecutive and systematic gain of resilience sources with the internal need to choose values.

The third stage becomes relevant for accepting any risk in life with a confidence that whatever happens to a mentee provides for his growth because of the knowledge he gets from the way of his life.

Implementing an educational position at an institution is not limited by just created comfortable conditions (facilities and resources, literature, empiric research, guidance and wonderful colleagues, etc.), but an environment of professionalism an educator creates and efficiency in the profession an educator was prepared for. The criteria of quality of the end results for an educator are the indicators of how the graduates enter a new environment and their growth in that new environment.

The implementation of the educational system of resilience was built on a principle that any phenomenon may be conceptualized - evidently - in a twofold way: either through comparing it to other likewise phenomena or through discovering its own unique nature. Studies of man, according to P. S. Gurevich, from "outside" supposes interpretation of a man's relations with the surrounding world of nature and culture (social environment) whereas the approximation to the man's mystery from "inside" is inherent with understanding the modus of the man's existence (bodily and spiritual, emotional and volitional) [11]. This approach allowed us to consider a native and spiritual pattern in the educational system we created (physical and emotional) with an opportunity to intensify the process of searching, gaining, and collecting knowledge of an expedient and organized process of shaping and developing a person (scientific and methodic). A good example of this is a theory of an educational system elaborated 45 years ago by N. V. Kuzmina (1980). We agree with the author and believe that in different years there were applied research based on that model.

The practical implementation of the resilience build-up system for orphans (2010-2019) at Azov Children Assistance Center showed that educators must be ready to realize three main components of their profession, namely motivational component, cognitive component, and operational and technical component [2].

In order to study a graduate's readiness for an independent living, we prepared and tested a system of research of the personal resilience characteristics. The personal resilience characteristics are basic and fundamental on the ground of four areas: educational (developed spiritual and moral sphere, level of general education and communicative skills), emotional (psychological) (behavioristic component, volitional activity, and motivational sphere level), social (self-realization level, readiness to enter universities and colleges, social wellbeing level) and physical (health level, physical development and physical fitness level) [2]. Each of the areas, in their turn, has three pattern characteristics that represent the peculiar features of a personality listed down in its pattern resilience characteristics.

In our opinion, studying the phenomenon of the children resilience intensifies the process of finding, gaining, and collecting knowledge and practical skills of educators as they shape and develop children personal resilience in the conditions of both institutions (like orphanages) and schools, colleges, summer camps.

It is especially important for us to continue our theoretical and practical research under the condition of holding a deep analysis of the successful Russian practices in the area of building up resilient persons. It is also important to remember that pedagogy is a science of 
patterns, matters, principles, methods, and forms of human education.

The problem raised here cannot be considered closed as we stand by the spring of its deep and wide streamway.

We hope to discuss this problem in our professional community.

As a supplement to the problem in question, it may be worth referring to the issue of life events [12].

According to F. Deutsch, a man and his surrounding mutually affect each other. It is important to consider age-related behavioral peculiarities and individual differences of men. The most important meaning is given to the life transforming events.

These events may happen in diverse areas including family, health, work; refer to age (childhood, school, marriage, etc.); to history (war, coups, economic crises, etc.); to lifetime tragedies of a man (disease, accidents, mishaps, etc.). Changing social roles may also be a life event.

Life events may be stress factors but may also promote a man towards new goals and their achievement. In this regard, it will be more than relevant to discuss personal resilience.

\section{References}

1. New Philosophic Encylopaedia, 2 (Mysl', Moscow, 2010)

2. B. Ramm, A Philosophic Encyclopedia. 2 (Soviet encyclopedia, Moscow, 1962)

3. Psychological Vocabulary (Academy of Pedagogical Sciences of the USSR, Moscow, 1983)

4. Psychology. Vocabulary (Politizdat, Moscow, 1990)

5. Unabridged Psychological Vocabulary (Prajm-Evroznak St. Petersburg, 2003)

6. E.A. Bayer, The Educational System of Orphan Resilience Build-Up by Means of Physical Training and Sports in Orphanages (Moscow, 2013)

7. A.M. Danilin, Mind-bending, Psychedelia, and The Addiction Phenomenon. - M, (Tsentrpoligraf, Moscow, 2001)

8. V.S. Mukhina, The Person: The Myths and The Reality (National Book Center, Moscow, 2017) 2000)

9. F.O. Brentano, On The Origin of The Moral Perception (Aleteiya, St. Petersburg,

10. S.R. Maddi, D.M. Khoshaba, Journal of Personality Assessment, 63 (1994)

11. P.S. Gurevich, Philosophic Anthropology (Omega-L, Moscow, 2010)

12. F. Deutsch, Psychological Encyclopedia (Piter, St. Petersburg, 2003) 